\title{
Explication of Emergency Dwellings in Turkey in the Context of Cultural Continuity: Fieldwork in Alagoz Village
}

\author{
Ferah Akinci, Kader Dağistanli \\ Faculty of Architecture, Yildiz Technical University, Istanbul, Turkey \\ Email: ferahakinci@gmail.com
}

Received September 14, 2012; revised October 23, 2012; accepted November 12, 2012

\begin{abstract}
The study is a fieldwork in Alagöz Village in Bingöl which is situated in the Eastern Anatolia Region of Turkey. Majority of the traditional houses in Alagöz Village were destroyed by earthquakes. Standard type houses were built within the scope of "Earthquake houses" project by the state under the initiative for closing the gap of housing. State adopted the resolution of demolishing the traditional houses and implemented such resolution as a consequence of standard type earthquake houses which do not fit with the cultural life of the region are not preferred by their users. Population who compulsorily started to live in "Earthquake Houses" began to utter their complaints. Even, they attempted to reconstruct and complete their partially demolished houses and returned to live in their traditional old houses. Forwhy, these houses fit with their social lives. Within this context the houses in the village compose of Traditional Houses, Earthquake Houses, houses they developed by being adversely affected from the Earthquake Houses. Each type of housing will be taken up within the scope of the study and their physical, social tissues will be analyzed and scrutinized, and as a result of this detailed study, conception of the region that is transmitted from past to today will be defined. In the study, it is emphasized that traditions which reached from past to today can not be ignored and should be taken into consideration by all means. Within this context, houses located in the region were analyzed as per their periods, opinions of the users were obtained and requests were highlighted in accordance with these findings and the houses which were developed in consequence of the requirements were scrutinized. Outputs were assessed on behalf of protecting the continuity in settlement and finalized with the clues of what are the obvious things to be done. For permanence of the settlement it is required to analyze the culture which preserved and protected its existence. Especially, in the countries such as Turkey, it is required to resolve the dynamics of the migration in consequence of various facts from rural areas to urban centers. It is required to provide approaches which may satisfy their needs and close their gaps by supporting the segment who is pleased with living in its village rather than creating new formations.
\end{abstract}

Keywords: Housing; Earthquake; Continuitibility; User Demand

\section{Introduction}

Generally speaking; besides being an indispensable need of human being, housing has reached the point today from cave dwellings, being consolidated by a concept of continuity and development. Due to the instinct of selfprotection from wild animals, the first space that human being formed, had an upgraded expectation after the settled life, is now constituted by living units which are produced by the intersection of interdisciplinary professions. The functions of the dwellings which are open to the innovative and developing technology has been interwove Ned with the culture. According to the definition which was done by the specialists of UNESCO (Dictionary of Social Sciences, UNESCO, 1964), culture is: "the consciousness that the society has about its historical continuity; namely, this society shows resolution to continue its existence and development with refer- ence to this consciousness." [1]. The physical environments, that are created by the sociocultural and economic structures of individuals who forms the society, present the awareness of their history to the new generations. The concrete formations (the physical environments); are one of the keys of sustainability. The essence is the sustainability of the structures, which has proved their permanence in time and their adaptation of development.

\section{Study Purpose and Scope}

Whatever their function is, the formations contradictory to the cultural continuity have made us question their permanence. This study, whose aim is to properly constitute a link between the past and the future, having clearness after the field study datum, emphasises the importance of the culture. Every architectural structure in 
the world is formed by referring positively or negatively the previous one. It is not suddenly occurred... In that respect; the study introduces the significance of the users in the permanence/life of the dwellings, therefore, by focusing on the dwelling scale, the reality that the culture of the life can not be ignored. In the societies; the spaces which are appropriate for the local conditions and show a functional harmony with the users and which are transferred through generations, are adopted as a traditional understanding.

In this article, the earthquake issue, which is one of the natural disasters that interrupt the continuity, is discussed. The studies after the earthquake should be carefully dealt with and well-organised. In this context, the experiences and the way of urban planning after the destroyable earthquakes in the world are important. In the article, the dwellings which are made due to the necessity after the earthquake are mentioned. The duty which underlines the need of a dwelling reformation adapted to the life style and the local culture even though they are destroyed by an earthquake, is sampled within Alagoz Village. It is analysed by means of the participants from Alagoz Village examining the dwellings done by the government for the injured people. The insertion of the typical emergency dwelling units in every region whenever needed is a very irritating approach. The spaces which exist for the users can not ignore the culture of the users.

\section{Earthquakes in Turkey}

There are several fault lines in Turkey. The most effective ones are the fault lines of Northern and the Eastern Anatolia.

When the magnitude and the effects of the earthquakes on earth are considered, two of the regions are very interesting seismic belts. The first one is Pacific seismic belt which surrounds the Pacific Ocean and has effects especially on Japan, the other one is Mediterranean-Himalaya seismic belt which spreads from Gibraltar to Indonesia and includes also Turkey. Owing to the fact that there are lots of small slabs among the bigger ones, a big portion of Turkey remains in the seismic belt (Figure 1). Turkey is under the impression of three big seismic slabs; Eurasia, Africa and Arabic slabs. The Anatolian slab, on which a great part of Anatolia sits, is a small part of the Eurasian slab [2]. The geography has a seismic character. Consequently, earthquake should be one of the primarily effective factors in the country planning. The post earthquake period should be dealt with in two stages and the urgent precautions and the later ones should be thoroughly evaluated from the scale of country to the region and to the unit structure. The fieldwork done in Turkey, province of Bingol, Village of Alagoz mentioned in this article will be a documentary for the precautions in the scale of rural area referring the unit structure.



Figure 1. Different seismic slab positions in Turkey.

\section{Emergency Dwellings in Turkey and around the World}

The construction is generally risky through the country. As a matter of fact the earthquakes in the past have shown that lots of people have lost their lives in the wrongly constructed buildings. The realm of the earthquake was better understood after the earthquake of 1999 which was also strongly felt in one of the most important cities of Turkey, in Istanbul. The modifications in the regulations are a result of this fact. The injured people who were confronted with the jerry built tents, and then maintained their lives for a period with "temporary housing system". Besides being prefabrically produced and plastic-based, the units of this type were preferred due to being also economic and easily constructible. The prefabricate units are an intermediary step for the injured people to have the permanent dwellings.

For the accommodation of the sufferers in a better housing, in the temporary dwellings time is gained. However, it is analysed that there are several unfavourable examples for such kind of "better" housing units when their ability in making up for the necessities of the users are considered. The units which were produced just in one type were not designed according to the geographical data. So, there were cases where factors such as the orientation and the culture were not evaluated. On the other hand, the psychology of an event in which the sufferer almost collided with death and lost his relatives was not taken into account and he was put into a similar type of dwelling [3]. Moreover, in the areas thought for the new housing formations after the earthquake of 1999 in Marmara Region, earthquake resistant dwellings in tunnel formwork type were constructed.

The ways in replying the housing necessity after earthquake show variety in the world. Managua, the capital city of Nicaragua [4], witnessed an earthquake in 1972. The need of the new dwellings was already evident as a problem in the city due to the increase in the population because of the immigration. By the earthquake, this existing problem got bigger. After the disaster, to urgently solve the problem "cities of tents" were formed; 
but they were not used owing to the inadaptability to the family life. The temporarily made wooden structures were not used either. Additionally, the igloos made by polyurethane foam were not a valid system due to the fact that they had the conditions to live in, after 5 months from the earthquake. The best solution for the victims was to stay near the relatives; or else to construct their own jerry built houses by using the materials collected from the wreckage. As a result of this a concept of "shanty house" was introduced. Some other part of the victims searched for a solution by staying in the cheap hostels. Hence, it was observed that the $95 \%$ of the quake victims accommodated in the houses of their relatives rather then in the emergency dwellings. What is more the following solutions for the permanent dwellings done in a more organised manner, did not also work. Blocks of houses from solid package concrete were executed. Another solution was the site which had a certain quality of living, but served to a limited number of habitants. However, the problems of the habitants came up and indeed the life style of the users sometimes contradicted the site's required understanding of life. It was observed that the dwellings were not adequate for the financial and cultural circumstances of the country. As a result of the fact that the urban land was not expropriated and the studies were not integrated with the urban plan, the governmental precautions remained deficient.

In 1963, Republic of Yugoslavia, the regional capital city of Macedonia, in Scopje [4], after the earthquake the tents were set up for the fist phase. The difficulties in planning the permanent dwellings were not seen because financial support arrived from a lot of country. The first planning approach after the earthquake was the ascertainment of damage in the buildings. The ones with repairable damage were again opened to use. Moreover, in the temporary dwelling stage no disadvantage was seen, because besides having a strong international spiritual and material support, the prefabrication system and the government being the land owner facilitated the period. Although the donations of the prefabricated units were reflecting the different architectural properties, in the whole concept they were harmoniously integrated. The works for not to stop the production in the country were also noteworthy. In the new dwellings, even though the national architectural references are valid, a discontinuity in the cultural sense is also evident. Nevertheless, generally speaking, Scopje had a successful transformation, due to an organised approach and a correct usage of the financial resources. Each construction exhibits the harmony in the whole.

\section{Scope of Fieldwork and Kigi District in Cultural Continuity}

Bingol is the city in which the fieldwork of the article,
Alagoz Village is found. It is located in the east of Turkey. It is in the region which remains between the fault lines of North Anatolia and the East Anatolia. The city has got 7 districts and 323 villages.

Bingol is an underdeveloped city which ranks the 71st in progress among other 81 cities of Turkey. According to the census of the year 2000 , the $70 \%$ of its population is engaged in agriculture. Although the main means of livelihood is kettle breeding, there has been a reduction by half in the number of great and small cattle since 1991 . Since 2002, the production of beehives has reached to 43,477 in number and therefore 796 tones of honey was obtained. Hence, beekeeping has become another important financial gain. Nevertheless there is unemployment in the city. The immigration rate from city to the countryside has increased. 2822 house of people returned to their villages up to the year 2002. In one hand the difficulty of earning money is the chief reason for immigration to the city, in the other hand there is a high rate of unemployment and not qualified labor force in the city [5].

The Alagoz village which is appurtenant to the Kigi district of Bingol presents an expedient dwelling character for this article. The cultural structure of the houses in the village which is transferred over generations is noteworthy. These houses were effected from the earthquake, confronted to an understanding of almost abandonment so as to find a solution to the disaster by the authorities. This region suffered from the earthquake and there is a problem throughout the country which stems from the culturally and functionally inappropriate applications. This problem needs to be solved.

The Alagoz village which is appurtenant to the Kigi district of Bingol city which is located in the eastern part of Turkey is selected as the fieldwork. On the west there is the city of Tunceli, on the North there are the cities of Erzurum and Erzincan, on the South there are the cities of Bingol, Elazig and Diyarbakir.

The district is $73 \mathrm{~km}$ far away from the city center of Bingol. But, since this said distance is valid for a gravel road, the destination to Bingol is provided by another road of $145 \mathrm{~km}$ which passes through Karakocan district of Elazig. The Alagoz village however is $27 \mathrm{~km}$ far from the district of Kigi. This road is alos a gravel road.

Being suffered by the disaster, lots of houses were damaged. The content of the study is, on one hand, these houses which are an expression of a cultural continuity and have been carried to today; on the other hand the dwellings which are constructed after the earthquake. Both types were estimated focusing on the user demands and were analysed referring to the system of their togetherness in the base of a common life style. In this analyse, the starting point was the idea that one of the products of the cultural accumulation which calls the 
societies into being must be "the house".

There is an accessibility problem in the village due to the heavy snow precipitation in winter; due to mud and landslides in the other seasons. After the earthquakes happened in 1968 and 2003, the houses were affected or totally destroyed, or survived partially damaged. The traditional houses have been a part of the local culture and the life style. The history of the district of Kigi, for instance, dates back to B.C. 3000. The Hittites, The Urartians and The Persians successively had dwelled in the region. The district had been under the domination of Seljukids, Akkoyunlus and Safevid Empire after 1071, and then Ottoman culture had been effective after 1514 . The presence of a through going culture is one of unquestionable realities.

The region has a continental climate. The summer is cool; the winter is long and brisk. The showers are usually seen in the autumn. The general vegetation type in the region is steppe. However there are also forested areas where the water rate is high. The most prevalent tree species are oak, juniper, wild poplar, willow, ash-tree and black tree. Other than those, apple, pear, walnut and mulberry trees can be planted as fruit giving trees [6].

While in the census of 1990 the population of the village was 115, it was indicated as 66 in the census of 2000 . This, therefore, demonstrates the change in the structure of the families of the village. $35 \%$ of the families has the children immigrated to the cities. Yet, there are a percentage of 30 in the village having a patriarchal family structure. In such kind of families, the father and (or) mother of the housefather, his wife, his unmarried children, his married male children, daughter-in-law and grand children share the same house. The family members of this kind of a family are $7-10$ in number. The educational level in the village is quite low. $50 \%$ of the population is primary school graduated, $10 \%$ is elementary school graduate, and just $7 \%$ is high school graduated. There is no university graduate in the village. The relatives and the neighbors live together as a large family in the whole village. The tradition of working together for the community or one of its members, gathers the relatives and the neighbors together for various works, and consequently the relations intensively continue. For instance, the women of the village come together on the roofs or terraces of the houses and do assorted works. The $40 \%$ of the population is over the age $50.65 \%$ of the families manage their lives by agriculture and cattle breeding, $25 \%$ by agriculture, cattle breeding and oldage salary, and the remaining $10 \%$ by only old-age salary [7].

The region has an appropriate structure for also beekeeping. The honey production has a district wide sales market and in Istanbul and is among the qualified productions. But there is hardly anyone who does this job in a professional manner.

Because there are no shops in the village for daily needs, the shopping is done by going to the district. For that reason, $90 \%$ of the people are not satisfied with the shopping conditions.

\section{Houses in Alagoz Settlement}

Generally speaking, there are two kinds of houses in the village; houses constructed by the villagers or by a craftsman and houses constructed by authorities. When the typolgy is more specifically examined, the houses of different understandings are seen. These are:

1) The traditional houses built by the villagers, survived from the late 19th century in which the village was established;

2) The houses built again by the villagers after 1950;

3) Reinforced concrete houses built by the owner with the help of the family members and the neighbours, between the years 2005 and 2006, instead of the houses destroyed by the government;

4) The permanent emergency houses built by the government in 1986;

5) The permanent emergency houses built by the government between the years 2005 and 2006.

\subsection{Traditional Houses Built by Villagers}

The traditional houses built by the villagers survived from the late 19th century when the village was established. These are the houses which reflects the culture of the village, has a history and prooved their permanency through the life. The local stone was used in a very talented manner in the structure of these houses. They were built as solid masonry and timber and stone were used as material. While the stone was used in the foundation and in the walls, the timber was used as a lacing course in the walls, ceilings, windows and the doors. The rooves of the houses are flat and covered by waterproof hardpan. owing to the slope, some of the houses were built with terraces and can be regarded as two-storey. The connection between the storeys is provided by exterior circulation. On the upper floor, there are living spaces, whereas on the lower floor there are kitchen, cellar, store, woodshed and animal shed. For the light penetration, the kitchen is on the front side of the house, while the animal shed is underground. The roof of the lower floor functions as the entranceterrace of the house.

The food is stored in the summer time, due to the long and snowy winters. Homemade macaroni, boiled and pounded wheat, dried layers of fruit pulp, canned food, and such kind of food for winter. are prepared collectivelly on the rooves of the houses. Besides, fruits and vegetables, such as wheat, barley, apple, pear, apricot, 
tomato, pepper, etc. are left to dry under the sun on the roof.

Those terraces are, at the same time, a kind of special spaces on which the villagers play various games. In the village where a coffe house does not exist, the men, for example, play game of checkers by drawing lines on the roof and utilizing the wooden pieces and the natural stone as the game stones. Moreover the children also prefer these areas to play line game and tipcat. Some of the houses in the village were built in single storey. For those ones, the spaces of kitchen, store and animal shed are formed in the independent units.

Because of the collective settlement, the houses do not have courtyards.however, the villagers have gardens and land around the village in which they grow various fruit and vegetable. Most of the houses were seriously affected from the earthquakes and damaged. The damaged ones were deserted by the governmental authorities and destroyed. Now, mainly the upper floors are seem to be collepsed and the lower floors are used as animal sheds. Some of the families prefered their damaged house rather than the emergency house and repaired the upper floors as they were before, using the same material.

\subsection{Houses Built Again by Villagers after 1950}

These houses are similar to the traditional ones, but they are constructed with different materials. Indeed the structure is finished by an inclined roof. As a binding material between the masonry walls, concrete is partially used. All of them are single storey. With a different solution, the space for the store is met by the utilization of attic. The entrance of this store, instead of an inner connection, is provided outside, by using the appropriate level of the slope. Additionally, the animal shed is built separately, but near to the house.

\subsection{Houses Built by Owners in 2005 and 2006}

Reinforced concrete houses were built by the owners with the help of the family members and the neighbours in 2005 and 2006 instead of the destroyed houses on the same land. Concrete and brick were used as building materials since the owners were influenced by the emergency dwellings done in the region. For the windows, a plastic based material was used instead of timber frames. In these houses whose design schema is similar to the traditional terraced houses, the kitchen is interpereted as a separate space.there is a fireplace inside the kitchen. The walls of the kitchen is masonry and thicker than the other walls of the house. The orientation of the rooms, for instance, is same as the previous house. The inclination of the roof is $40 \%-45 \%$ and the attic space is used as the store. The animal sheds are considered in the units close to the house.

\subsection{Permanent Emergency Houses Built by Government in 1986}

Therse are the houses which were constructed by the government. They were built in a permanent manner in 1986 for the families whose houses were damaged in the earthquake of 1968. the construction was done in an empty land close to the settlement border of the village. The emergeny dwellings were desigend by governmental architects and they all have the same spatial organization and plan. These projects were designed by Ministry of Public Works and Settlement without any consideration of local identity, user profile, culture, geographic conditions and orientation. They were propesed to the public as single houses and detached houses. The families were faced to back to back way of living by the introduction of such detached houses. However, the villages irrationally formed by the single houses were directed to a reluctant rational organization. Besides, the kitchen became a space in the house, whereas in the understanding of life the space for the kitchen was created indepentedntly or semi-independently to the house.

The traditional "Architectural Products Without the Architects", namely the emergeny dwellings with one type projects were not favorably used due to their irrelavant design to the traditions of the village. $70 \%$ of the users who lives in those houses because they have to, attached some additional spaces according to their traditions and needs. Kitchen was added to $65 \%$, entrance terrace was added to $90 \%$, toilet was added to $50 \%$ and courtyard was added to $80 \%$ of the used houses. Yet, $90 \%$ of the users ponited that they had willingly made those attachments. The attached kitchens also had the fireplace

\subsection{Permanent Emergency Houses Built by Government in 2005 and 2006}

The permanent emergency houses built by the government between the years 2005 and 2006 for the earthquake happened in Bingol in 2003. they were constructed by a method which is called "aid for the self-house builders". This method, however, did not worked in practice and the constructers mediated a settlement with the government on one project type and excecuted the "country style single storey emergency house" (2roomed). Differently from the others, these were built on the previous site of the damged houses. The bathroom and the toilet were seperated and instead of gable roof, an icnlined roof was applied. The crafstman and the building materials are much more better than the other permanent emergency dwellings.

These houses which only have a combination with the local culture in the logic of sheltering does not present an example of the cultural continuity. 


\subsection{Evaluation of Houses in Alagoz}

The natural environmental data of the geography and the socio-economic factors have a significant role in the formation of a building. In this context, the houses of Alagoz Village are evaluated in terms of natural environment and socio-economical factors. The houses are divided into two groups according to their construction phases. These are; the houses built by the villagers on their own or by the help of a craftsman (The traditional houses built by the villagers, survived from the late 19th century in which the village was established, The houses built again by the villagers after 1950, Reinforced concrete houses built by the owner with the help of the family members and the neighbours, between the years 2005 and 2006, instead of the houses destroyed by the government) and the houses built by government (The permanent emergency houses built by the government in 1986).

\subsubsection{In Terms of Natural Environmental Factors}

1) Traditional dwellings have been built considering the climatic data such as orientation, wind,etc. According to the climatic data, the houses have been oriented to the South or to the west as well, when the site is not appropriate in order to benefit from the sunlight inside the houses.

2) To provide the thermal insulation small scaled windows have rather been reduced in dimension on the North or comletely removed. Because of the long period of snowy weather in the region, to diminish the load on the roof, the inclination of the roof have been prefered in between $40 \%-45 \%$.

3) In typically planed emergency dwellings, instead, the climatic considerations have not been taken into account, as a result of the disorriented dwelling, the same spaces have been oriented to different directions. There are also houses whose entrance and two wide Windows oriented to the North.

4) It is observed that the traditional houses have been harmaonically settled on the topography, integrated with the site and the terraces have been formed in an accordance to the natural balance.

5) The inharmonious and environment-independent texture of the emergency houses which has a grid plan schema, instead, is structured differently from the organic traditional village dwelling and does not establish a relationship with topography.

6) In the tradional houses, the natural materilas are used which are directly related to the climate and vegetation and traditional construction methods are applied. In the buildings of the village the stone is mostly used and in various parts timber is prefered. The material is integrated with the environment due to its relation with the nature.

7) In the emergency houses, instead, contemporary industrial construction materilas are used. To provide the material economically is a current criteria. Because of the reinforcedconcrete and brick are the most available and the cheapest material, they have been prefered in these constructions like all over the country. In addition to that, owing to the capacity of heat absorbtion of reinforcedconcerete framework construction system and the hollowed brick wall is less then the traditional stone houses, they provide less thermal insulation; hence, whereas the house heats immediately in the summer, it can not heat in the winter and gets cold earlier.

\subsubsection{In Terms of Socio-Cultural Environmental Factors}

1) The traditional houses have been formed with respect to the life style and principle necessities.the spaces and the spatial relations have been determined in this frame kitchen, for insatance, decided seperately from the living spaces. Flat rooves have been occured which constitutes an open space for a lot of traditional work.

2) Contradictionally in the emergeny houses, a standard user profile is referred and their design is made typically all over the country. As a result of this, spaces were created which do not respond the needs of the users. Therefore, various attachments were made to those houses.

3) The family structure and the neighbourhood have been effective in the forming of the traditional houses. The distrubution of the spaces was affected from the family structure and multifunctionality was adopted as principle. The spaces were thought to gather and work collectivelly.

4) In the emergency houses, instead, the family structure was not taken into consideration and the multifunctionality of the spaces was not given importance, hence the rooms of private uses were designed. The organization and the scale of the rooms had a number of negative side.the spaces of common use were not also considered.

5) The traditional houses were generated under the influence of the relation between agricultural and cattlery production. Considering this situation, near or underneath the houses, animal sheds and the stores were built. Moreover, the houses were configured and the number of the rooms were determined according to the economic condition of the family .

6) In the emergency houses, instead, the construction finance was prior to the family structure and an economic solution was aimed at. the necessary spaces such as for animal sheltering, agricultural equipment and product storage were not even minded.

7) Politics and the law were not effective on the 
reconstruction of the new traditional buildings, on the contrary did prevent them from living.

8) The excecuted emergency houses have indeed a lot of negative sides as a result of the various strategies of application.

When the user-built and government-built houses are compared, it is seen that the traditional houses are more superior in many aspects. These buildings are the most harmonious structures to either the natural effects and local culture. The houses built by government are not harmonious to the natural effects and do not reflect the local culture of the village in terms of visuality.

There is a great difference between the construction characters in terms of visuality. While the masonry of the region introduces a characteristic understanding to the region, in the new buildings this understanding have been abondoned.

In the context of the abovementioned issues, emergency dwellings are a product of inaccurate planning and design in terms of either cultural approach and the choice of physical material and its application. The first step to take in the village is to research the reasons of the damage in the traditional houses after the earthquake and if they are repairable and have the possibility of living inside again. In reconstructing the buildings harmonious to the local geography,climate and the culture instead should be formed without disturbing the existent texture of the village.the houses should be built suitable to the pyhsical and social values by integrating the modern life conditions and technology. The village should present a healthy way of living with either infrastructure and superstructure.

\section{Recommendations for Future Projects}

The climatic factors should be taken into consideration, the necessary comfort for human beings should be provided, in the construction the existent natural materials of the region should be predominantly used, the topographical data should be minded and the texture of the village should be continued in some degree. As a matter of fact, for a permananet housing approach in a small poppulation village, the harmony with the local culture should be prior to the easy construction methods.

The spatial organization should be created according to the dominant socio-cultural life in the village. The productivity dependent to agriculture and cattle breeding should be evaluated as an architectural data. Furthermore, since the sector of agriculture and cattle breeding are supported in the developement plan of the country, the villages such as Alagoz should be reconsidered by a more powerful strategy. Therefore, the expectations of the families reimmigrating to their villages from Bingol will find an productive occupation. The conditional immigration concept will be avoided both to constitute a balance of the population in the country and not to detach the people of the villages from their identities. Throughout Turkey, the potential young population flowing to the big cities to find a job, becomes disappointed and do not have permanent living conditions neither in the city, $\mathrm{nr}$ in their villages. For that reason, the decisions taken for the villages will definetely provide benefit for the approach of the country planning. What is more, the bee keeping occured as a new job in Alagoz village should be promoted by the government specifically in the village it self. While the world is supporting the ecological formatios, it is conradictory to deny them. The emergency houses built for overcoming the all mentioned problems, cauesed more problematic situations after their realization, since the only issue regarded as criteria was the finance in the preconstruction period.

In this context, the values should be protected and the houses in the frame of continuity should be built with a consideration of "permanancy" in Turkey. The architectural modification in Alagoz Village is an example of a "cut off" in the cultural continuity and throughout Turkey, these typical problems are evident. To take a lesson from the experiences and orienting to the future will provide the permanency in the global world.

\section{REFERENCES}

[1] N. Köseoğlu, "National Culture and Identity," Ötüken Publications, İstanbul, 1992, p. 147, (in Turkish).

[2] Sanal Gazete Web Site (in Turkish). http://www.sanalgazete.com.tr/deprem/

[3] N. F. Akınc1, "The Aftermath of Disaster in Urban Areas: An Evaluation of the 1999 Earthquake in Turkey", Citıes, Vol. 21, No. 6, 2004, pp. 527-535.

[4] I. Davis, "Housing Recommendations for Post Earthquakes," Translated and İnterpreted by F. Oymak, Architecture Journal, Vol. 14, No. 147, 1976, pp. 10-14, (in Turkish).

[5] F. Bayrak, Ş. Ünal and H. Taşçı, "Parliamentary Human Rights Investigation Commission Bingol Report," 2003, (in Turkish). http://insanhaklarimerkezi.bilgi.edu.tr

[6] Kigi District Governship Web Site, (in Turkish). www.kigi.gov.tr

[7] K. Dağıstanl1, "Architecture without Architect and a Study on Bingöl, Kığı, Alagöz Village,” Masters Thesis, Architectural Design Program, Institute of Science, Yildiz Technical University, İstanbul, 2007, (in Turkish). 